\title{
ESCOLARIDADE E VARIAÇÃO NA PRODUÇÃO ESCRITA: UMA ANÁLISE SOCIOLINGUÍSTICA DO FENÔMENO DA CONCORDÂNCIA VERBAL
}

\author{
Ronaldo Adriano de Freitas
}

\begin{abstract}
RESUMO
Este artigo apresenta uma reflexão sobre o papel da escolaridade no processo de variação linguística. Após uma breve revisão bibliográfica, desenvolvemos a análise da variação do fenômeno da concordância verbal em redaçóes produzidas em uma instituição escolar a fim de verificar qual o peso do fator escolaridade na realização da concordância verbal nas formas padrão ou populares/estigmatizadas.
\end{abstract}

PALAVRAS-CHAVE: sociolinguística; efeito-escola; concordância verbal.

\section{Introdução}

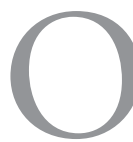

surgimento da Sociolinguística nos Estados Unidos nos anos $60^{1}$ foi um movimento de extrema importância para as ciências da linguagem, em função das mudanças de paradigmas em relação ao estruturalismo e ao gerativismo, introduzindo, no âmbito das investigaçóes linguísticas, a questão do uso, com sua variabilidade e suscetibilidade aos agentes externos. Segundo Camacho:

1 Embora as ideias de Meillet sejam reconhecidas como precursoras nos estudos sociolinguísticos, sendo citadas por Labov (2008, p. 218) em seus trabalhos, consideramos que a sistematização da disciplina e o alcance de seus efeitos são devedores do grupo que tem Labov como seu principal representante. 
Um dos postulados da linguística do início do século XX é o de que o objeto da linguística deveria identificar-se com a parte homogênea dos fenômenos observáveis. Na segunda metade desse século, a sociolinguística representou uma ruptura significativa com o formalismo teórico mediante a introdução do conceito de variável linguística, mas, ao mesmo tempo, dele se aproximou ao adotar o conceito de regra variável. (CAMACHO, 2010)

Tal movimento teve como consequências diretas a sistematização do estudo das variantes linguísticas estigmatizadas pela sociedade, o reconhecimento científico da legitimidade dessas variantes e o despertar para a necessidade de uma abordagem pedagógica que considerasse a heterogeneidade como intrínseca à língua, e não como um defeito ou mal a ser combatido.

É com base nesses fatores que o presente artigo apresenta, a partir da noção de variação linguística - conceito central dessa teoria -, uma análise do impacto do fator "escolaridade", tomado como um dos fatores linguísticos responsáveis por essa variação. Objetiva-se verificar, por meio da análise da produção escrita de alunos de diferentes séries escolares, se a passagem pelo período em que se determina através do currículo escolar o estudo do fenômeno da concordância verbal é capaz de produzir mudanças sensíveis aos olhos da análise sociolinguística em relação à realização ou não das variantes preconizadas pela gramática normativa.

Essa análise se fará, conforme exposto acima, a partir dos princípios da sociolinguística laboviana; no entanto, não deixaremos de fazer aqui reflexôes que inter-relacionem esses princípios à Análise do Discurso e à História das Ideias Linguísticas, relaçóes essas que têm sido objeto de nossos estudos. Trata-se de argumentar que, concomitantemente à variabilidade das estruturas linguísticas, os jogos de linguagem estão sujeitos ao funcionamento ideológico historicamente construído, o que submete os efeitos de sentido ao funcionamento das estruturas de poder vigentes na sociedade e questiona a possibilidade de neutralidade científica diante de tais estruturas.

A análise do papel da escolaridade no processo de variação da língua tem dupla motivação: por um lado, estuda-se o funcionamento da própria língua, verificando de que forma as práticas escolares, entendidas como práticas sociais coercitivas, interferem na sua estrutura e promovem a estabilização de suas formas (mudança linguística). Por outro lado, avalia-se/questiona-se a 
capacidade da instituição escolar de promover o aprendizado do aluno das formas características da norma padrão, isto é, de cumprir o seu papel de garantir a ascensão social dos alunos que mais necessitam, uma vez que, se o domínio da norma padrão não representa a garantia de crescimento profissional e status social, a sua falta representa uma barreira quase intransponível para uma grande parte da população brasileira.

A metodologia que empregaremos para tal análise consiste na revisão bibliográfica inicial, pela qual sustentaremos o ponto de vista de análise; e no exame da produção textual de alunos da primeira e da terceira série do ensino médio, a fim de se verificar as formas de comparecimento das variantes relacionadas à concordância verbal. Salientamos que o programa curricular da escola analisada prescreve para o segundo ano o trabalho com a questão da concordância verbal; desse modo, analisaremos a relação entre as formas de realização da concordância e os fatores extralinguísticos informados pelos alunos, a fim de se observar se a escolaridade produziu resultados significativos na adequação da linguagem ao nível de monitoramento esperado para um texto escolar.

\section{A teoria sociolinguística}

A teoria laboviana representou a ruptura com a linguística praticada na primeira parte do século XX. Até então a linguística era centrada no estruturalismo de Saussure, que embora reconhecesse a língua como um fenômeno social, e enfatizasse ser a parte social, e não a individual, a que interessava à linguística, acreditava ser possível atingir essa parte do fenômeno da linguagem pela análise de um único falante. Também a linguística de Chomsky, que despontava no início da segunda metade do século XX, se mostrava uma linguística centrada no indivíduo, deixando de considerar a influência dos fatores externos no processo de produção da língua e com isso deixava de lado a questão da mudança linguística.

Desse modo, para as duas tendências, a linguagem humana se reduz a um sistema estável, imutável, de formas linguísticas submetidas a uma norma e as leis que governam esse sistema estável são especificamente linguísticas, internas, por estabelecerem ligaçóes entre signos, formas e relaçóes no interior de um sistema fechado. (CAMACHO, 2010) 
Ao lançar as bases de suas teorias e ao desenvolver em parceria com diversos linguistas os estudos que fundariam a disciplina Sociolinguística, Labov não tinha a preocupação de criar uma nova ciência, mas trazer para a linguística aspectos fundamentais que até então ela havia ignorado. É dele a argumentação de que a Sociolinguística não constituiria uma disciplina, mas uma metodologia da linguística, de modo que o autor não vê diferença entre Linguística e Sociolinguística, já que toda Linguística deveria ser, portanto, social: "Se não houvesse necessidade de contrastar esse trabalho com o estudo da língua fora de seu contexto social, eu preferia dizer que se trata simplesmente de linguística". (LABOV, 2008, p. 246, grifo do autor).

Labov não distingue variável sociolinguística de variável linguística. (...) o autor deixa claro que, ao realizarmos estudos sociolinguísticos, não estamos somente preocupados em verificar a relevância dos fatores sociais, mas, antes disso, objetivamos obter um retrato da estrutura gramatical da língua, vista como um fenômeno social. (MONGUILHOTT, 2010, p. 48)

Aliando a teoria linguística às condições de produção científica que permitiram desde o registro tecnológico dos registros de fala até à apropriação do tratamento estatístico e mesmo dos fundamentos da gramática gerativa, a Sociolinguística alcançou seu espaço nas ciências da linguagem e tornou obrigatório a todo pesquisador em linguística o conhecimento de seus princípios, que passaram a ser considerados em áreas distintas da inicialmente estabelecida. Isso representa uma vitória da teoria laboviana ao argumentar que,

é através do estudo da linguagem em seu contexto social que a quantidade de dados se expande enormemente, oferecendo, assim, meios de decidir que análise é a correta dentre as alternativas possíveis. Para sustentar essa posiçáo, Labov adota o conceito de variaçáo e o insere definitivamente nos estudos linguísticos, como uma propriedade inerente, constitutiva da linguagem. (CAMACHO, 2010) 
Essa vitória pode ser traduzida como a inclusão do 'uso' como um dos objetos da linguística e a análise de corpus como uma de suas mais importantes ferramentas, o que se observa em grande parte da pesquisa linguística moderna, dos estudos do discurso aos da gramaticalização, passando pelas correntes da psicolinguística e da sociocognição, a componente sociolinguística é sempre um fator de peso na elaboração da teoria.

\section{Faces da sociolinguística}

No desenvolvimento da Sociolinguística no Brasil, três frentes se destacam em relação aos objetivos de estudo. Uma de abordagem estrutural, próxima da etnolinguística; outra, ideológica, de cunho político e militante; e uma última, a pedagógica, que trata da questão do ensino pelo viés da Sociolinguística. O funcionamento dessas frentes, embora produza resultados distintos, é profundamente indissociável, já que compartilham epistemologicamente as mesmas bases.

No campo estrutural, os trabalhos sociolinguísticos têm produzido uma diversidade de materiais úteis à compreensão do funcionamento da língua e ao refinamento teórico, como atlas linguísticos, gramáticas da fala, gramáticas de uso bem como teorias acerca do contato linguístico. Já no campo da militância sociolinguística, encontramos a abordagem da luta política pela valorização/ legitimação das formas não padrão, mas praticadas por grandes comunidades linguísticas, e o combate ao preconceito linguístico, entendido como forma de exclusão social e instrumento de poder.

Por último, a abordagem pedagógica liga-se às duas anteriores para elaborar uma crítica ao sistema tradicional de ensino, preconizando tanto a dimensão do reconhecimento das variedades não padrão praticadas pelo aluno quanto a necessidade de construção de instrumentos linguísticos que legitimem certos usos como parte da norma padrão, em detrimento de formas da norma padrão com pouca ocorrência mesmo entre falantes altamente escolarizados, levando à construção de materiais didáticos e instrumentos de avaliação que contemplem essa realidade.

Nesse cenário de preocupação dos estudos linguísticos, em geral, críticas severas têm sido dirigidas aos professores, mais especifi- 
camente aos de língua portuguesa, aos quais é delegada a missão de ensinar leitura e escrita. Os pesquisadores anteriormente citados atestam em seus estudos problemas de várias ordens: os professores usam uma variedade de língua que os alunos não compreendem; não consideram as experiências linguísticas que os alunos trazem para a escola, não deixando espaço para a fala dos alunos, portanto só eles têm sempre o direito à palavra sem haver interlocução; e ainda demonstram não conhecer a realidade econômica, social e cultural do grupo social dos alunos. (IBIAPINA, 2012, p. 02)

É importante notar que o reconhecimento dos estudos sociolinguísticos, que se iniciaram no Brasil a partir dos anos 70, e mais especificamente na segunda metade da década de 80 , vem produzindo inúmeros resultados, explicitamente citados nos Parâmetros Curriculares Nacionais, documento que guia a produção pedagógica brasileira e institui, no campo das políticas de ensino, a questão da variação como aspecto primordial nas práticas pedagógicas. É nessa vertente que fundamentamos o presente trabalho e para ela nos voltaremos em nossas análises, não sem antes as correlacionarmos com o programa História das Ideias Linguísticas, ao qual nos filiamos em nosso posicionamento epistemológico.

\section{Sociolinguística e História das Ideias Linguísticas - HIL}

A História das Ideias Linguísticas - tal como proposta por Auroux na França (2001) - conduziu à reflexão sobre o papel dos instrumentos linguísticos no desenvolvimento das civilizaçóes, procurando considerar o impacto da história do desenvolvimento das ciências e ideias relacionadas à linguagem e seus desdobramentos na estrutura das línguas, das relaçóes sociais e dos acontecimentos históricos. Por outro lado, a Análise do Discurso Francesa (AD), fundamentada nas ideias de Pêcheux, desde seus primórdios, já se confrontava epistemologicamente com as bases do conhecimento linguístico, ao questionar suas fronteiras e ao propor que o conhecimento científico não se dissocia do político e do ideológico. A interface entre essas disciplinas permitiu o desenvolvimento de uma análise crítica da constituição da língua nacional brasi- 
leira, a qual aponta os reflexos do discurso colonizador (MARIANI, 2004) na formulação dos instrumentos linguísticos aqui produzidos e o peso ideológico das tradiçôes e das relações de poder na formulação de uma língua imaginária que dita o que seriam os bons costumes nas práticas linguísticas.

Os trabalhos da HIL, embora se diferenciem da Sociolinguística em função de alguns posicionamentos teóricos, aproximam-se de seus trabalhos que tematizam a questáo do preconceito linguístico, da legitimidade das variantes populares, da artificialidade da norma padrão ensinada e exigida no âmbito escolar; temas basais para o desenvolvimento da linguística, de ampla aplicação na questão do ensino e de forte repercussão no meio midiático, artístico, literário e científico. É assim que se justifica posicionamento como o de Berenblum:

Em toda nação uma única variedade de língua se impóe como língua legítima e, é interessante ressaltar, essa variedade está associada a determinados setores (dominantes) que conseguiram se impor e que geralmente representam as camadas médias e urbanas. Assim, a variedade parcial que constitui a chamada língua oficial é produto de decisóes políticas num momento histórico específico da história de cada nação. Uma determinada variedade adquire o reconhecimento de língua oficial e se impóe como legítima através de processos políticos de unificação que se desenvolvem no transcurso da constituição dos Estados nacionais. (BERENBLUM, 2005, sp)

A autora ressalta ainda a importância das políticas de ensino de línguas na formação dos estados nacionais: "É interessante ressaltar que todas essas produçôes destacam o papel central da língua na própria definição das naçôes e sua função fundamental na construção do sentimento de nacionalidade com elas associado" (BERENBLUM, 2005). Apresenta também o papel dos processos de elaboração dos instrumentos linguísticos na constituição do Estado, o qual se estabiliza pela monopolização do poder, o que inclui o poder de definição da codificação de uma norma padrão, que se dá, entre outros, pelo funcionamento dos sistemas educacionais. 
A escola será a encarregada de transmitir, inculcar e reforçar a variedade oficial da língua, ao mesmo tempo em que contribui para a criaçáo, valorizaçáo e consolidação de uma cultura nacional, integrada por mitos de origem, símbolos e representaçóes acerca das próprias histórias das naçôes e da essência do ser nacional. (BERENBLUM, 2005)

Essa postura se mostra coerente com as posiçôes firmadas no campo da sociolinguística, demonstrando a validade da interface entre esses campos da linguística.

\section{O fator escolaridade e o efeito-escola nos índices educacionais}

Em todos os textos consultados para o presente trabalho, o fator escolaridade é apontado como uma variável determinante para o processo de variação linguística. Segundo Mollica (2003, p. 28), "a escolarização tem sido testada amplamente para se verificar o grau de influência sobre os falantes quanto à apropriação das normas de prestígio". Não obstante a isso, não é tarefa elementar definir o efeito da escolarização no processo de variação linguística. $\mathrm{O}$ processo de escolarização é um processo de reforço de outras estruturas sociais; as escolas atendem a grupos sociais específicos e tendem a formar comunidades de fala que refletem fatores sociolinguísticos extraescolares.

Um bom exemplo desse funcionamento se verifica na divulgação das médias do ENEM, o exame nacional do ensino médio. O ranking das escolas demonstra que apenas as instituiçóes que atendem as classes sociais mais elevadas figuram entre as mais bem colocadas. Essa constatação nos conduz à reflexão sobre a capacidade da escola de influenciar o padrão sociolinguístico praticado pelo aluno. Até que ponto o bom desempenho linguístico dos alunos não é decorrente simplesmente de outras práticas sociais, servindo a escola apenas de instrumento de repetição dessas situaçóes?

Esses questionamentos coincidem com o posicionamento de diversos sociólogos da educação, que apontam a escola como um instrumente de manutenção das estruturas de poder. Destacamos aqui a fala de Bourdieu, que aponta a escola como uma estrutura de reprodução das desigualdades sociais: 
em virtude da lentidão do processo de aculturação, diferenças sutis ligadas à antiguidade do acesso à cultura continuam a separar indivíduos aparentemente iguais quanto ao êxito social e mesmo ao êxito escolar. A nobreza cultural também tem seus graus de descendência. (BOURDIEU, 1989, p. 6)

Torna-se assim um grande desafio medir o "efeito-escola" - entendido como a capacidade institucional de produzir modificaçóes na estrutura sociocognitiva do indivíduo - na questão do desenvolvimento das habilidades linguísticas relacionadas ao domínio da norma padrão, já que, via de regra, as melhores escolas não são as que são capazes de garantir o aprendizado aos alunos com dificuldades, mas as capazes de selecionar os melhores alunos, de quem se pode exigir maior compromisso e desenvoltura nas práticas escolares.

A pesquisa, que ora se delineia, tem por fim investigar o peso de dois anos de escolaridade sobre alunos de uma escola pública considerada de excelência, O Instituto Federal de Educação, Ciência e Tecnologia Fluminense, no campus Campos-centro, na cidade de Campos dos Goytacazes, no norte fluminense. Trata-se de questionar se a dita excelência (por diversas vezes "comprovada" por resultados em exames como o ENEM) é fruto da ação pedagógica da escola ou do efeito do processo seletivo de entrada, que acaba por filtrar os alunos "mais capazes", apenas atuando no sentido de reproduzir as desigualdades que lhe são externas.

Se, contrariamente a isso, é papel da escola promover o aprendizado justamente daquele que não sabe; é sua missão estabelecer mecanismos para o desenvolvimento da articulação linguística nos diversos níveis de monitoramento. Deve fazer parte da política linguística de toda instituição o atendimento aos que mais necessitam de apoio para o domínio das estruturas da língua que lhes são estranhas.

\section{A concordância verbal}

A questão da concordância verbal como elemento caracterizador do domínio das formas da norma padrão revela-se um importante instrumento para se compreender o efeito-escola na estrutura variacional. Tal como assinala Vieira: 
A não realização da regra de concordância verbal, no português do Brasil, constitui, sem dúvida, um traço de diferenciação social, de cunho estigmatizante, que se revela, com mais nitidez, no âmbito escolar. O forte contraste entre o uso ou não do mecanismo de concordância e as políticas de ensino, espelhadas em práticas didático-pedagógicas fundamentas em gramáticas que pressupóe uma norma única. Constituem exemplos da necessidade de conhecerem e descreverem as regras em uso pelas diversas comunidades de falantes. Assim sendo, parece que o primeiro passo para o estabelecimento de uma metodologia adequada ao ensino da concordância verbal é o conhecimento real dos fatores que presidem à opção de falante pela aplicação ou não dessa regra, visto que o cancelamento da marca de número no SV não é categórico. (VIEIRA, 2007 p. 01)

Tal análise se dará a partir do tratamento de variável sintática, preconizando que a teoria da variação linguística pode ser aplicada a níveis linguísticos acima da fonologia, o que amplia o escopo de análise inicial da disciplina. Tal quais os trabalhos de Monguilhott (2010), de Vieira (2012) e de Silva (2007), temos por variável dependente deste estudo, a concordância verbal de formas da terceira pessoa do plural. Tal como apontado por Vieira (2012) e Silva (2008), trata-se de variante bastante estabilizada nas esferas escolares, inclusive em função do estigma das variantes não padrão relacionadas à concordância verbal:

É conhecimento dos que se preocupam com o ensino de língua portuguesa que a concordância verbal é um tema bastante valorizado nas salas de aula, principalmente no que se refere à avaliação da produção textual dos alunos, em função de sua forte caracterização sociolinguística: o não-uso da marca explícita de concordância representa um traço de diferenciação social, de modo geral estigmatizante. (SILVA, 2007)

Vieira Rodrigues aponta que "entre falantes escolarizados, a concordância é bastante produtiva, principalmente se o sujeito está anteposto e próximo 
ao verbo, mesmos fatores condicionadores da ausência de marca entre não-cultos.” (VIEIRA, 1997, p. 119). O papel dessa variante é, portanto, um importante indicador do efeito-escola, uma vez que se trata de elemento amplamente valorizado, cujo domínio é requerido por grande parte da sociedade. Por sua vez, trata-se de conteúdo vinculado ao processo seletivo de entrada do aluno na instituição avaliada; logo, acredita-se que boa parte dos alunos já dominem essa norma antes da entrada na escola, o que minimiza os efeitos da escolarização nesse local.

\section{A análise}

A análise ora apresentada leva em consideração o pressuposto laboviano que elenca a alternância estilística, segundo o qual não existem falantes de estilo único; há alternância de variantes de acordo com o contexto social e o tema. São considerados juntamente com esse pressuposto, mas alterados em função do objeto de pesquisa em questáo, a necessidade da busca pelo vernáculo, que é substituído pela busca do vernáculo alterado pelas práticas escolares, elaborando-se para esse fim uma pergunta que retrata uma questão ligada à segurança - tema de ordem pública, mas de efeitos íntimos -, a fim de suscitar o maior envolvimento possível do entrevistado. Assim, por tratar de uma prática escolar, a questão da formalidade, um dos axiomas apontados por Labov, é levada em conta e considerada, nesse caso específico, um aspecto positivo. Por fim, toma-se o axioma laboviano a respeito da qualidade dos dados, segundo o qual a melhor forma de coleta de dados é a gravação de entrevistas individuais; no entanto, levando em consideração os objetivos desse trabalho, optamos pela coleta de dados de forma escrita. Tal como dispóe Silva:

A escolha de textos da modalidade escrita para a constituição do corpus deveu-se à crença de que "a influência da escola na aquisição da língua não deve ser procurada no dialeto vernáculo dos falantes - em seu estilo mais coloquial -, mas sim em seus estilos formais monitorados." (Bortoni-Ricardo, 2005, p. 130). Pretendeu-se também observar o grau de assimilação das estruturas da norma de prestígio nos textos dos estudantes e verificar uma possível progressão na sua competência linguística no que 
concerne à concordância. Essa a razão de se analisarem redaçôes de alunos que estavam em ciclos de estudos progressivos. (SILVA, 2008)

A partir dos trabalhos de Silva (2008) e Vieira (2012), foram levados em consideração, como fatores para a realização ou não da regra de concordância verbal, as questóes da posição do sujeito em relação ao verbo (anteposto ou posposto) e a passividade verbal marcada por pronome. No entanto, em função da restrição do material coletado, o único registro observado foi o da posição do verbo, o que ocorreu em número pequeno, náo permitindo a sistematização dos dados produzidos. Creditamos as limitaçóes dos dados produzidos à tentativa de produzir um questionário que provocasse uma resposta relativamente espontânea do entrevistado, o que resultou em um grande número de respostas não aproveitáveis para o estudo em questão, conforme veremos na próxima seção.

Ao todo foram aplicados 85 questionários sem identificação dos informantes, dos quais se selecionaram 60 para a análise, em função de se buscar um equilíbrio entre o número de entrevistados em cada série escolar. Nesse universo de 60 textos analisados, apenas 30 produziram oraçóes em que a terceira pessoa do plural, objeto dessa análise, foi utilizada. Esse fato já é relevante, pois aponta para a necessidade de um questionário mais estrategicamente elaborado em futuros trabalhos, a fim de se provocarem as formas que se pretenda analisar.

O questionário aplicado apresentava duas partes: na primeira, três questôes de múltipla escolha levantavam informaçóes sobre a renda familiar, o nível de escolaridade dos pais e os hábitos de leitura e estudos dos entrevistados. $\mathrm{Na}$ segunda parte, o questionário apresentava a seguinte pergunta:

Como os problemas da falta de segurança têm afetado sua vida? Você já viveu algum acontecimento desse tipo, ou já teve alguém de seu convívio que tenha passado por alguma ocorrência traumática? Relate sua experiência e fique à vontade para manifestar sua opiniáo sobre o assunto. 


\section{Análise do efeito-escola sobre a variação}

Nos 30 questionários analisados, foram registradas 53 oraçôes com verbos na terceira pessoa do plural, das quais 49 se apresentavam na ordem direta e apenas 5 eram formadas por sujeito posposto ao verbo. Das quarenta e nove oraçôes na ordem direta, apenas cinco apresentavam estruturas sem as marcas de concordância da norma padrão; e das cinco orações com sujeito posposto, apenas uma. Estatisticamente tais informaçóes podem ser representadas da seguinte forma:

Tabela 1. Percentual de desvios em relação à norma padrão

\begin{tabular}{|c|c|c|c|}
\hline \multicolumn{2}{|c|}{ ORDEM DIRETA } & \multicolumn{2}{c|}{ SUJEITO POSPOSTO } \\
\hline Norma padrão & $\begin{array}{c}\text { Forma } \\
\text { variante }\end{array}$ & Norma padrão & $\begin{array}{c}\text { Forma } \\
\text { variante }\end{array}$ \\
\hline $89,8 \%$ & $10,2 \%$ & $75 \%$ & $25 \%$ \\
\hline
\end{tabular}

Essa informação é compatível com os números apresentados por Vieira e Pires na análise de redaçóes de vestibular, que levou em consideração um número muito maior de dados e conta com informantes muito mais comprometidos com os resultados de sua produção. Expomos aqui os resultados desse trabalho, a fim de se evidenciarem as semelhanças por meio de análises paralelas.

Tabela 2. Desvios em relação à norma padrão - pesquisa paralela

\begin{tabular}{|l|c|c|}
\hline Variantes & Dados & Percentual \\
\hline Ausência de marca de concordância & $189 / 2516$ & $7,5 \%$ \\
\hline Presença de marca de concordância & $2327 / 2516$ & $92,5 \%$ \\
\hline
\end{tabular}

(fonte: Vieira e Pires, 2012)

Também assim como no trabalho paralelo, “[o]s resultados obtidos mostram que a possibilidade de não realização padrão da concordância é menor quando o sujeito está anteposto ao verbo”. (VIEIRA e PIRES, 2012) 
Tabela 3. Posição do sujeito - pesquisa paralela (fonte: Vieira e Pires, 2012)

\begin{tabular}{|l|c|c|c|}
\hline $\begin{array}{l}\text { Posiçáo do sujeito em } \\
\text { relaçáo ao verbo }\end{array}$ & Valor Absoluto & Valor Percentual & Peso Relativo \\
\hline Sujeito anteposto & $125 / 1831$ & 6,8 & .48 \\
\hline Sujeito posposto & $15 / 126$ & 11,9 & .70 \\
\hline
\end{tabular}

Levando em consideração os objetivos de nossa pesquisa que, em lugar de procurar descobrir de fato o padrão sociolinguístico de uma comunidade, busca investigar o efeito-escola sobre a produção linguística, tabulamos os dados obtidos cruzando as informaçóes referentes aos desvios em relação ao padrão e os fatores: nível de escolaridade dos pais, renda familiar, curso e série escolar.

No que diz respeito à escolaridade dos pais, retomamos o posicionamento de Bourdieu citado na seção O FATOR ESCOLARIDADE E O EFEITO-ESCOLA NOS ÍNDICES EDUCACIONAIS, segundo o qual as tradiçóes familiares funcionam como uma espécie de herança cultural, o que possibilitaria melhores resultados de alunos cujos pais tenham escolaridade elevada. Para isso, solicitamos ao entrevistado informar o nível de escolaridade mais alto de um de seus pais (ou responsáveis legais). Para fins estatísticos, em função da pequena quantidade de dados, agrupamos as escolaridades "superior" e "pós-graduação" no grupo "nível superior", e os demais, no grupo "nível básico", uma vez que essa divisão possibilitou uma divisão balanceada dos registros.

Tabela 4. Distribuição dos entrevistados por escolaridade dos pais

\begin{tabular}{|l|c|c|}
\hline Escolaridade dos pais & $\begin{array}{l}\text { Número de } \\
\text { informantes }\end{array}$ & Percentual \\
\hline Nível superior & 17 & $56 \%$ \\
\hline Nível básico & 13 & $44 \%$ \\
\hline
\end{tabular}

Considerando a distribuição dos registros não padrão entre os níveis mencionados, chegamos aos seguintes números: dentre os 17 entrevistados cujos pais possuem nível superior, $7,7 \%$ utilizaram a forma variante, enquanto dentre os 13 cujos pais possuem formação básica, 23,5\% utilizaram essa forma. 
Tabela 5. Uso das variantes não padrão por escolaridade dos pais

\begin{tabular}{|c|c|}
\hline \multicolumn{2}{|c|}{ Escolaridade dos pais } \\
\hline Básico & Superior \\
\hline 23,5 & 7,7 \\
\hline
\end{tabular}

Quanto ao quesito renda familiar, a sistematização dos dados feita de forma semelhante à realizada no item escolaridade produziria resultados estatisticamente similirares, no entanto, o estudo da variável renda familiar não se mostrou tão produtivo, uma vez que há forte concentração de renda na classe mediana (segundo tabela da Fundação Getúlio Vargas), o que impede que os valores estatísticos produzidos permitam alguma interpretação indicadora de qualquer regularidade. Apenas 6 entrevistados declararam possuir renda familiar considerada alta (acima de $\mathrm{R} \$ 4.591,00$ ). Dentre esses, apenas um utilizou uma forma não padrão. A porcentagem de entrevistados que utilizou as formas não padrão é idêntica.

Tabela 6. Distribuição dos entrevistados por renda familiar

\begin{tabular}{|l|c|c|}
\hline Renda familiar & $\begin{array}{l}\text { Número de } \\
\text { informantes }\end{array}$ & Percentual \\
\hline Classe alta & 6 & $20 \%$ \\
\hline Demais classes & 24 & $80 \%$ \\
\hline
\end{tabular}

Tabela 7. Porcentagem do uso das variantes não padrão por renda familiar

\begin{tabular}{|c|c|}
\hline \multicolumn{2}{|c|}{ Renda familiar } \\
\hline $\begin{array}{l}\text { Classe } \\
\text { alta }\end{array}$ & $\begin{array}{l}\text { Demais } \\
\text { classes }\end{array}$ \\
\hline $16 \%$ & $16 \%$ \\
\hline
\end{tabular}

Finalmente, apresentamos o resultado referente à variável escolaridade, objetivo principal de nossa reflexão. Tradicionalmente esperaríamos que os anos de escolaridade refletissem em um uso maior das variantes padrão; no entanto, nossa hipótese inicial apontava, a partir dos pressupostos da sociologia 
da educação e da prática profissional docente, que a influência da escolarização não seria determinante diante dos demais fatores analisados. Os resultados de nossa análise confirmam essa hipótese.

Tabela 8. Distribuição dos entrevistados por escolaridade

\begin{tabular}{|l|c|c|}
\hline Escolaridade & $\begin{array}{l}\text { Número de } \\
\text { informantes }\end{array}$ & Percentual \\
\hline $1^{\text {a }}$ série & 21 & 70 \\
\hline $3^{\text {a }}$ série & 9 & 30 \\
\hline
\end{tabular}

Tabela 9. Porcentagem do uso das variantes não padrão por escolaridade

\begin{tabular}{|c|c|}
\hline \multicolumn{2}{|c|}{ Escolaridade } \\
\hline $1^{\text {a }}$ série & $3^{\text {a }}$ série \\
\hline $9,52 \%$ & $33,3 \%$ \\
\hline
\end{tabular}

Destacamos que, incialmente, foram analisados 60 formulários, de modo a se garantir o mesmo número de entrevistados por série; todavia, nessas entrevistas, apenas 30 apresentaram as variantes em estudo, e de forma assimétrica.

Afirmar que, entre os alunos da $3^{\text {a }}$ série do ensino médio, 33\% fizeram uso das variantes não padrão, enquanto na primeira série menos de $10 \%$ fizeram esse uso, pode causar certo estranhamento; contudo, dois fatores devem ser considerados: 1) o nível de monitoramento dos alunos da $1^{\text {a }}$ série é muito maior (o que se comprova também pelo número de respostas dos que fizeram uso da terceira pessoa do plural, revelando um maior grau de comprometimento desse aluno com a instituição, enquanto os alunos do terceiro ano mostram-se menos integrados à instituição, já que apenas se encontram nela em função de atrasos no calendário letivo devido às consecutivas greves); 2) a distribuição da escolaridade dos pais - fator extralinguístico que se mostrou importante na produção do registro da norma padrão - apresenta grande concentração entre alunos da $1^{\text {a }}$ série, o que se mostra coerente com a hipótese inicial de que o efeito-escola não é determinante no domínio das formas linguísticas da norma padrão. 


\section{Considerações finais}

As diversas faces da sociolinguística apresentam-se como importantes instrumentos para a compreensão da estrutura linguística e das formas de organização da sociedade. $\mathrm{Na}$ interface com outras disciplinas, pudemos registrar nesse trabalho a importância da compreensão da heterogeneidade linguística como constitutiva da linguagem e da construção da norma padrão como forma de legitimação das estruturas sócio-históricas de dominação e subordinação social. Por outro lado, consideramos que, uma vez instituídas essas formas, é papel da escola tanto se manifestar contrariamente às formas institucionalizadas de preconceito contra as variedades populares da língua, como garantir ao seu público o acesso a essa variedade supostamente superior, a fim de garantir o acesso de seu público aos bens culturais e ao poder simbólico materializado nas formas linguísticas registradas como padrão.

Vimos, no entanto, que o fator "escolaridade" se mostra menos decisivo para o domínio dessa variedade que outros fatores sociolinguísticos de acesso mais restrito, o que contribui para a manutenção das desigualdades sociais e segregação econômica, nesse momento de nossa história caracterizado pela ampla oferta de escolarização. Dessa forma, como um estudo que tem como principal objetivo ser um esboço de futuros trabalhos que investiguem mais a fundo a relação escolaridade/norma padrão, encerramos nossa análise na certeza de ter produzido a almejada contribuição.

Esperamos em trabalhos futuros analisar uma maior quantidade de dados, tanto no que diz respeito ao número de entrevistados como na análise de variantes, uma vez que a observação inicial dos textos avaliados já levantou ensejo para outras análises que se mostram pertinentes para o estudo da questão.

Outrossim, esperamos também que os resultados demonstrados sejam capazes de despertar na prática docente o desejo de pesquisa por alternativas capazes de ampliar a eficácia do efeito-escola em relação ao domínio da norma culta, a fim de que a escola possa cumprir o seu papel social, colaborando para a redução da pobreza, melhoria da qualidade de vida e a construção de novas estruturas políticas, econômicas e sociais em nosso país. 


\section{Referências}

BERENBLUM, A. As definições de língua correta no contexto educacional: uma leitura do discurso docente - 2005. Anais do 15 seminário da $A L B$, http:// alb.com.br/arquivo-morto/edicoes_anteriores/anais15/Sem 12/andreaberenblum.htm, 15 jan. 2015.

BOURDIEU, P. A escola conservadora: as desigualdades frente à escola e à cultura. Educação em Revista. Belo Horizonte (10) 3-15 - 1989, http://educa. fcc.org.br/pdf /edur/n10/n10a03.pdf, 15 jan. 2015.

CAMACHO, R. G. Uma reflexão crítica sobre a teoria sociolinguística. DELTA, Sáo Paulo, v.26, n. 1,2010, http://www.scielo.br/scielo.php?script=sci arttext\&pid= S0102-44502010000100006\&lng=en\&nrm=iso, 12 Jan. 2015.

CALLOU, D. Gramática, variação e normas. In: VIEIRA, S. R.; BRANDÃO, S. (Orgs.). Ensino de gramática: descrição e uso. São Paulo: Contexto, 2007.

IBIAPINA, D. F. Variação linguística em sala de aula de língua portuguesa: uma abordagem etnográfica. Anais do SIELP. Volume 2, Número 1. Uberlândia: EDUFU, 2012, http://www.ileel.ufu.br/anaisdosielp/wp-content/uploads/2014/06/volume_2_artigo_089.pdf., 15 jan. 2015.

LABOV, W. Padróes Sociolinguísticos. Trad. Marcos Bagno. São Paulo: Contexto, 2008.

MARIANI, B. Colonização linguistica. Campinas: Pontes, 2004.

MOLLICA, M. C. Relevância das variáveis não linguísticas. In: e BRAGA, M. L. (Orgs.) Introdução à sociolinguistica: o tratamento da variação. São Paulo: Contexto, 2003.

MONGUILHOTT, I. O. S. Variação na concordância verbal de terceira pessoa do plural no PB e no PE. Anais do IX Encontro do Círculo de Estudos Linguisticos do Sul, Palhoça, 2010, http://www.celsul.org.br/Encontros/09/ artigos/Isabel\%20Monguilhott.pdf, 15 jan. 2015.

SILVA, E. V. Concordância verbal: variação e ensino. Anais do XICNLF, 2007, http://www.filologia.org.br/xicnlf/10/concordancia_verbal.pdf, 15 jan. 2015.

. Norma, variação e ensino: a concordância verbal. Cadernos de Letras da UFF-Dossiê: Literatura, língua e identidade, n. 34, p. 31-41, Niterói, 2008.

VIEIRA, S. R. A não-concordância em dialetos populares: uma regra variável. Revista Grafos. vol.1, n.2, 1997, http://periodicos.ufpb.br/ojs/index.php /graphos/article/view/9201/4896, 15 jan. 2015. 
e PIRES, J. C. P. Padróes variáveis de concordância verbal em redaçôes de vestibular: restrições e avaliação. Matraga, v.19, n.30, Rio de Janeiro, jan./jun. 2012, http://www.pgletras.uerj.br/matraga/matraga30/arqs/matraga30a08.pdf, 15 jan. 2015.

\title{
EDUCATION AND CHANGE IN WRITING PRODUCTION: SOCIOLINGUISTIC ANALYSIS OF SUBJECT-VERB AGREEMENT
}

\begin{abstract}
This paper presents an analysis on the role of education in the language variation process in Portuguese. After a brief literature review, we developed the analysis of the variation of the subject-verb agreement phenomenon in writings produced in a Brazilian school institution in order to verify the education factor weight in achieving subject-verb agreement in standard forms or popular/ stigmatized.
\end{abstract}

KEYWORDS: sociolinguistics; school effect; subjectverb agreement.

Recebido em: 04/04/2015

Aprovado em: 26/09/2015 